УДК 665.612 .2

\title{
УТИЛИЗАЦИЯ РАЗНОРОДНЫХ НЕФТЯНЫХ ГАЗОВ В УНИВЕРСАЛЬНОЙ МАЛОЭМИССИОННОЙ ГАЗОТУРБИННОЙ УСТАНОВКЕ С ВНЕШНИМ ПОДОГРЕВОМ ТОПЛИВНОГО ГАЗА
}

\author{
Шилова Алена Алексеевна ${ }^{1}$, \\ alyona1203@gmail.com \\ Бачев Николай Леонидович1, \\ bnl54@yandex.ru \\ 1 Пермский национальный исследовательский политехнический университет, \\ Россия, 614990, г. Пермь, Комсомольский пр., 29.
}

\begin{abstract}
Актуальность исследования обусловлена необходимостью создания отечественных газотурбинных энергоустановок с универсальной малоэмиссинной камерой сгорания для утилизации нефттяных газов с различным содержанием балластирующих компонентов. В последнее время предложены и исследуются различные способы снижения эмиссии вредных веществ в газотурбинных двигателях (гомогенное горение, впрыск воды или пара, дифффузионное горение по схеме «богатое горение - резкое разбавление - бедное горение» (RQQL) и т. д.). В данной работе предлагается и исследуется вариант низкотемпературного и малоэмиссионного горения с внешним подогревом нефтяного газа перед его подачей в утилизационную камеру сгорания.

Цель: разработать термодинамические модели определения режимных параметров утилизационной энергоустановки с подогревателем топливного газа в ее составе и выявить влияние степени забалластированности нефртяного газа на коэфрфициенты избытка воздуха и расходные характеристики в камере сгорания для мощностного ряда энергоустановок.

объекты: утилизационная газотурбинная энергоустановка, подогреватель топливного газа, малоэмиссионная камера сгорания. Методы: термодинамическое моделирование утилизационной газотурбинной установки с подогревом нефтяного газа перед его подачей в камеру сгорания и термодинамический расчет параметров низкотемпературного малоэмиссионного горения обедненной газо-воздушной смеси.

Результаты. Получены режимные параметры утилизационной газотурбинной установки и подогревателя топливного газа в ее составе. Для нефртяных газов с различным содержанием балластирующих компонентов определены минимальные температуры подогрева, при которых возможно устойчивое горение. Определены потребные значения коэффрициента избытка воздуха и расходные характеристики для семейства энергоустановок. Даны рекомендации по выбору диаметра камеры сгорания для мощностного ряда утилизационных энергоустановок.
\end{abstract}

\section{Ключевые слова:}

Забалластированный топливный газ, низкотемпературное малоэмиссионное горение, внешний подогрев топливного газа, устойчивое горение, мощностной ряд установок.

\section{Введение}

При разработке новых отечественных микрогазотурбинных утилизационных установок или при их получении конвертацией вспомогательных установок разного назначения центральное место занимает создание малоэмиссионной камеры сгорания (КС) с устойчивым горением топливного газа $[1,2]$. Разработка малоэмиссионной КС значительно усложняется, если разрабатывается универсальная КС для утилизации нефтяных газов (НГ) с различным содержанием балластирующих компонентов и теплопроизводительностью $[3,4]$.

К настоящему моменту времени предложены и разрабатываются различные конструктивные компановки низкоэмиссионных КС в составе газотурбинных установок (ГТУ). Привычные и известные действия для снижения эмиссии вредных веществ в КС традиционных схем являются компромиссом между выбросами несгоревших углеводородов иугарного газа, с одной стороны, и выбросами оксидов азота, с другой стороны [5-11]: сжиганиепредварительно перемешанной обедненной топливной смеси в «сухих» КС; применение «мокрых» КС с диффузионным факелом и впрыском пара (воды); каталитическое сжигание (полное окисление) топливно-воздушной смеси; дополнительное использование каталитической очистки выхлопных газов ГТУ.

В работах [12-18] теоретически обоснован иэкспериментально подтвержден новый способ расширения концентрационных пределов горения газов при интенсификации предпламенных процессов с помощью внешнего подогрева компонентов. В исследованиях показано, что низкотемпературное сжигание бедных горюче-воздушных смесей (ГВС) при высоких значениях коэффициента избытка окислителя один из перспективных методов снижения эмиссии вредных веществ в стационарных ГТУ.

В данной работе рассматриваются вопросы организации низкотемпературного малоэмиссионного бедного горения при предварительном внешнем подогреве топливного газа.

Работы [19-22] посвящены экспериментальным исследованиям влияния начальной температуры топливного газа на верхние и нижние пределы горения. Результаты экспериментальных и теоретических исследований о влиянии начальной температуры горючего на нижний предел горения представлены в работе [23]. В работах [24-27] указывается, что предварительный подогрев топливного газа перед его подачей в КС расширяет пределы горения и можно организо- 
вать низкотемпературное горение на бедном пределе. Реализация такого типа горения позволила бы разрабатывать неохлаждаемые однозонные КС в составе утилизационных установок.

Для внешнего подогрева топливного газа предлагается использовать теплообменник в составе ГТУ, в котором топливный газ (вторичный теплоноситель) нагревается отработанными на турбине газами (первичный теплоноситель). Тогда область устойчивого горения определяется не только составом утилизируемого газа, но и режимными параметрами подогревателя топливного газа в составе установки.

С одной стороны, область горения ограничивается значениями коэффициента избытка окислителя на нижнем пределе $\left(\alpha_{\mathrm{H}}\right)$, полученными методом флегматизации и зависящими от состава топливного газа $[28,29]$. С другой стороны, область горения ограничивается значениями коэффициента избытка окислителя по параметрам установки $(\alpha$ гту $)$, полученными из решения уравнения энергетического баланса с учетом температуры топливного газа на входе в камеру сгорания. Значения этой температуры, в свою очередь, определяется режимными и геометрическими параметрами теплообменника-подогревателя. Использование универсальной КС для утилизации НГ при разных степенях забалластированности предполагает наличие универсального теплообменника, который обеспечивает неизменное значение температуры топливного газа на входе в камеру сгорания.

Одним из определяющих факторов, влияющих на облик и потенциальные возможности газотурбинной энергоустановки, является степень сжатия компрессора $\varepsilon$. Поэтому проведен параметрический анализ мощностного ряда энергоустановок (разные значения полезной мощности) с использованием семейства тербокомпрессоров (различные значения $\varepsilon$ ) при разных составах утилизируемого газа. В результате этого анализа выработаны рекомендации по выбору диаметра КС из условия устойчивого положения фронта пламени.

\section{Термодинамическая модель расчета режимных параметров газотурбинной установки с внешним подогревом топливного газа}

На рис. 1 представлена принципиальная схема ГТУ с внешним подогревателем топливного газа с однозонной неохлаждаемой утилизационной КС.

Компрессор - 1 обеспечивает подачу окислителя (воздуха) в камеру сгорания - 4. Система подачи топливного газа - 5 состоит из ресивера и редуктора. Перед подачей в камеру сгорания -4 топливный газ нагревается в теплообменном аппарате - 6 отработанными на турбине - 2 газами. Внешний подогрев топливного газа позволяет осуществить низкотемпературное, малоэмиссионное горение на нижнем пределе в однозонной неохлаждаемой КС.

Режимные параметры компрессора

- Удельная работа сжатия

$$
H_{\mathrm{K}}=c_{p}^{\mathrm{o \kappa}} \cdot T_{\mathrm{oK} . \mathrm{BX}}^{\mathrm{K}} \cdot\left(\varepsilon^{\frac{k-1}{k}}-1\right) \cdot \frac{1}{\eta_{\mathrm{K}}},
$$

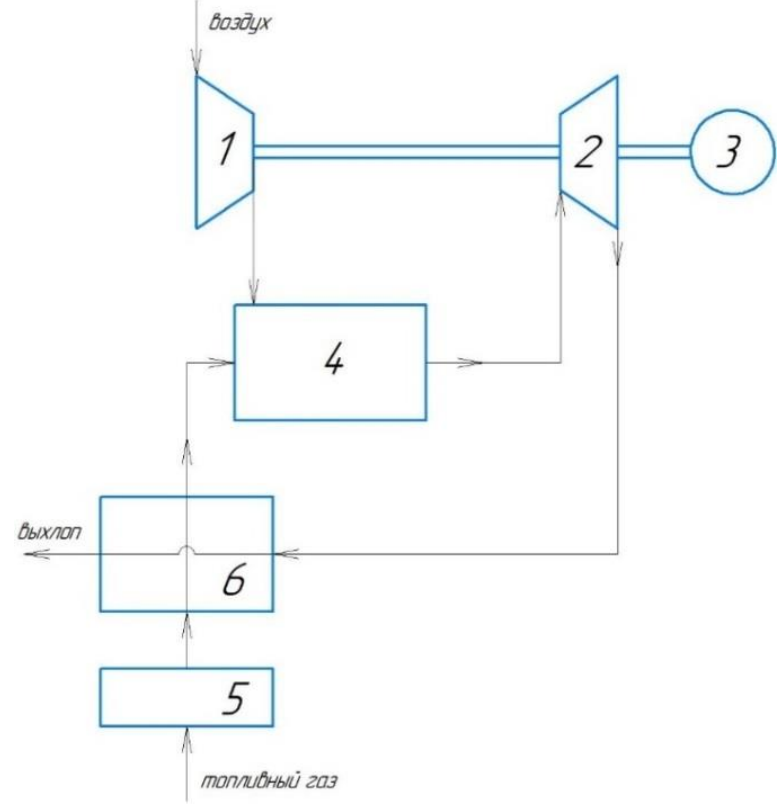

Pис. 1. Принципиальная схемагазотурбинной установки с внешним подогревателем топливного газа с однозонной неохлаждаемой утилизачионной камерой сгорания: 1 - компрессор; 2 - турбина; 3 - электрогенератор; 4 - камера сгорания; 5 - система подачи топливного газа; 6 - подогреватель топливного газа

Fig. 1. Schematic diagrams of a gas turbine plant with an external fuel gas heater and a single-zone uncooled recovery compressor station: 1 - compressor; 2 - turbine; 3 -electric generator; 4 - combustion chamber; 5 -fuel gas supply system; 6 -fuel gas heater

где $c_{\text {р.ок }}, k$ - удельная изобарная теплоемкость и показатель адиабаты окислителя (воздуха); $T_{\text {ок.вх }}^{\text {к }}$ температура окислителя (воздуха) на входе в компрессор; $\varepsilon, \eta_{\text {к }}$ - степень сжатия и КПД компрессора.

- Давление на выходе

$$
P_{\text {ок.вых }}^{\mathrm{\kappa}}=P_{\text {ок.вх }}^{\mathrm{K}} \cdot \varepsilon,
$$

где $P_{\text {ок.вх }}^{\mathrm{\kappa}}$ - давление на входе в компрессор.

- Температура на выходе

$$
T_{\text {ок.вых }}^{\mathrm{K}}=T_{\text {ок.вх }}^{\mathrm{K}}+\frac{H_{\mathrm{K}}}{c_{\text {р.ок }}} .
$$

Режимные параметры турбины

- Степень расширения на турбине

$$
\delta=\lambda \cdot \varepsilon,
$$

где коэффициент потерь по газовоздушному тракту $\lambda=0,93 \ldots 0,96$.

- Удельная работа расширения

$$
L_{\mathrm{T}}=c_{p}^{\text {газ }} \cdot T_{\text {газ.вх }}^{\mathrm{T}} \cdot\left(1-\frac{1}{\delta \frac{k-1}{k}}\right) \cdot \eta_{\mathrm{T}},
$$

где $c_{\text {р.газ, }} k$ - удельная изобарная теплоемкость и показатель адиабаты рабочего тела турбины; $T_{\text {газ.вх }}^{\mathrm{T}}$ температура рабочего тела на входе в турбину; $\eta_{\text {т }}$ КПД турбины.

- Давление рабочего тела на выходе из турбины 


$$
P_{\text {газ.вых }}^{\mathrm{T}}=\frac{P_{\text {газ.вх }}^{\mathrm{T}}}{\delta},
$$

где $P_{\text {газ.вх }}^{\mathrm{T}}$ - давление рабочего тела на входе в турбину.

- Температура рабочего тела на выходе из турбины

$$
T_{\text {газ.вых }}^{\mathrm{T}}=T_{\text {газ.вх }}^{\mathrm{T}}-\frac{L_{\mathrm{T}}}{c_{p}^{\text {газ }}} .
$$

\section{Система подачи топливного газа}

Предполагается, что в систему подачи топливного газа будут входить редуктор и ресивер.

- Давление топливного газа на выходе из редуктора

$$
P_{\text {гор.вых }}^{\text {ред }}=P_{\text {гор.вх }}^{\text {кс }}+\Delta P_{\text {гор }}^{\text {та }}
$$

где $\Delta P_{\text {гор }}^{\mathrm{Ta}}$ - потери давления топливного газа в теплообменном аппарате; $P_{\text {гор.вх }}^{\text {кс }}$ - давление топливного газа на входе вКС.

- Температура топливного газа на выходе из редуктора

$$
T_{\text {гор.вых }}^{\text {ред }}=T_{0} \cdot\left(\frac{P_{\text {гор.вых }}^{\text {ред }}}{P_{0}}\right)^{\frac{k-1}{k}},
$$

где $P_{0}, T_{0}$ - давление и температура топливного газа в ресивере; $k$ - показатель адиабаты топливного газа.

\section{Режимные параметры камеры сгорания}

- Температура топливного газа на входе в КС после внешнего подогрева

$$
T_{\text {гор.вх }}^{\text {кс }}=T_{\text {гор.вых }}^{\text {ред }}+\mu \cdot\left(T_{\text {газ.вых }}^{\mathrm{T}}-T_{\text {гор.вых }}^{\text {ред }}\right) .
$$

Коэффициент рекуперации $\mu$ показывает степень использования тепла первичного теплоносителя и влияет на выходные характеристики, поверхность и габариты теплообменного аппарата.

- Температура окислителя (воздуха) на входе в КС без дополнительного подогрева

$$
T_{\text {ок.вх }}^{\mathrm{Kc}}=T_{\text {ок.вых }}^{\mathrm{K}} .
$$

- Коэффициент избытка окислителя (воздуха) в камере сгорания по параметрам установки определяется из энергетического баланса для КС и равен

$$
\alpha_{\text {Гту }}=\frac{1}{K_{m 0}} \cdot \frac{c_{p}^{\text {гор }} \cdot T_{\text {гор.вх }}^{\text {кс }}+H u \cdot \eta_{\text {г }}-c_{p}^{\text {газ }} \cdot T_{\text {газ.вх }}^{\mathrm{T}}}{c_{p}^{\text {га3 }} \cdot T_{\text {газ.вх }}^{\mathrm{T}}-c_{p}^{\text {оК }} \cdot T_{\text {оК.вх }}^{\text {Кс }}},
$$

где $c_{\text {р.гор }}, H u$ - изобарная теплоемкость и теплопроизводительность топливного газа; $\eta_{\text {г }}$ полнота сгорания топливного газа; $K_{m 0}-$ массовое стехиометрическое соотношение.

\section{Расходные и энергетические характеристики}

- Полезная работа установки

$$
L_{\text {пол }}=L_{\mathrm{T}}-H_{\mathrm{K}} \text {. }
$$

- Массовый расход рабочего тела через турбину

$$
m_{\text {газ }}^{\cdot}=\frac{N_{\text {пол }}}{L_{\text {пол }}} .
$$

- Массовый расход топливного газа

$$
m_{\text {гор }}^{\cdot}=\frac{m_{\text {газ }}^{\cdot}}{1+\alpha_{\text {Гту }} \cdot K_{m 0}} .
$$

- Массовый расход окислителя (воздуха)

$$
m_{\text {ок }}=m_{\text {газ }}^{\cdot}-m_{\text {гор }}^{\cdot}
$$

- Мощность, вырабатываемая турбиной

$$
N_{\mathrm{T}}=m_{\text {газ }} \cdot L_{\mathrm{T}} .
$$

- Потребная мощность на привод компрессора

$$
N_{\mathrm{K}}=m_{\mathrm{ок}} \cdot H_{\mathrm{K}} \cdot
$$

- Коэффициент полезной мощности

$$
\varphi=\frac{N_{\text {пол }}}{N_{\text {т }}} .
$$

- Коэффициент полезного действия энергоустановки

$$
\eta_{\text {гту }}=\frac{N_{\text {пол }}}{m_{\text {гор }}^{\cdot} \cdot H u} .
$$

Коэффициенты избытка окислителя (воздуха) на

\begin{tabular}{|c|c|c|c|c|}
\hline $\begin{array}{c}g_{\text {бал }}, \text { мac. \% } \\
\text { Ballast } \\
\text { fractions, } \\
\text { wt. \% }\end{array}$ & $\begin{array}{l}c_{\mathrm{p}}^{\text {гор }}, \frac{\text { Дж }}{\mathrm{\kappa} \cdot \mathrm{K}} \\
\mathrm{c}_{\mathrm{p}}^{\text {fuel }}, \mathrm{J} \\
\cdot \mathrm{kg}^{-1} \mathrm{~K}^{-1}\end{array}$ & $\begin{array}{c}\text { Коэффици- } \\
\text { ент адиабаты } \\
k, \\
\text { Adiabatic } \\
\text { index, } k\end{array}$ & $\begin{array}{c}\mathrm{Hu}, \frac{\text { МДж }}{\mathrm{\kappa \Gamma}} \\
\Delta \mathrm{H}, \mathrm{MJ} \\
\cdot \mathrm{kg}^{-1}\end{array}$ & $\begin{array}{c}\text { Стехиометри- } \\
\text { ческое соотно- } \\
\text { шение } K_{\mathrm{mo}} \\
\text { Air-fuel ratio } \\
\text { AFR }\end{array}$ \\
\hline 0 & 2448 & 1,268 & 50,1 & 15,544 \\
\hline 15 & 1970 & 1,150 & 40,7 & 12,383 \\
\hline 40 & 1722 & 1,176 & 30,4 & 9,008 \\
\hline 67 & 1448 & 1,212 & 19,2 & 5,554 \\
\hline 79 & 1310 & 1,278 & 11,9 & 3,394 \\
\hline 89 & 1190 & 1,322 & 6,6 & 1,792 \\
\hline
\end{tabular}
нижнем пределе горения подогретого топливного газа $\alpha_{\text {н }}$ определялись по методике, описанной в [27].

Характеристики малоэмиссионного низкотемпературного горения с внешним подогревом нефтяного газа с различным содержанием балластирующих компонентов

В таблице представлены результаты термохимических расчетов для реальных нефтяных газов (НГ) различных месторождений Российской Федерации [30] с различным содержанием балластирующих компонентов $g_{\text {бал }}$.

Таблица. Термодинамические характеристики забалластированных нефтяных газов

Table.Thermodynamic characteristics of ballasted petroleum gases

Расчеты по определению областей устойчивого горения проводились для разных энергоустановок со степенями сжатия на компрессоре $\varepsilon$ в диапазоне от 1,8 до 5,5. На рис. 2 в качестве примера показаны графические зависимости $\alpha_{\mathrm{H}}=f\left(T_{\text {гор.вх }}^{\text {кс }}\right) \quad$ и $\alpha_{\text {Гту }}=f\left(T_{\text {гор.вх }}^{\text {кс }}\right)$ для НГ с процентами забалластирванности от 0 до 89 мас. \% для энергоустановки со степенью сжатия $\varepsilon=3$.

Анализ данных показывает, что границы устойчивого горения забалластированного топливного газа в однозонной неохлаждаемой КС сильно зависят от температуры подачи в КС топливного газа. Существует минимальная температура подогретого топливного газа $T^{*}$, при которой начинается устойчивое горение в утилизационной КС. Для каждой состава топливного газа и энергоустановки эта температура имеет свое определенное значение. 


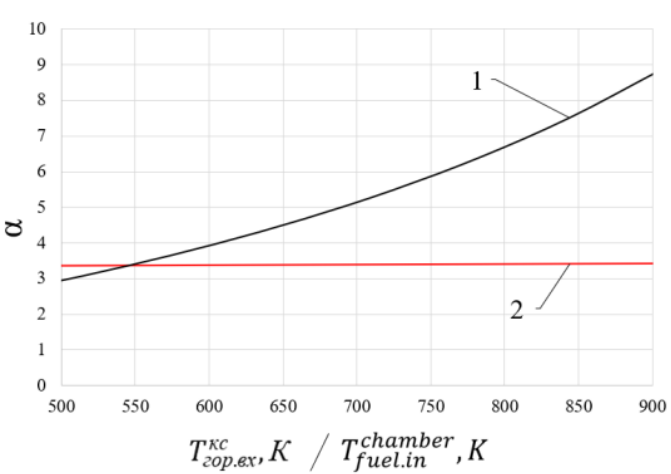

a) $g_{\text {бал }}=0$ мас. $\%$

a) ballast fractions 0 wt. \%

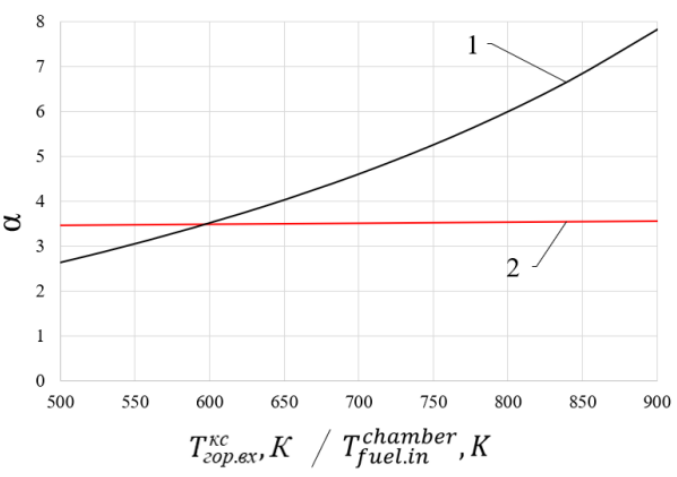

в) $g_{\text {бал }}=40$ мас. $\%$

c) ballast fractions $40 \mathrm{wt} . \%$

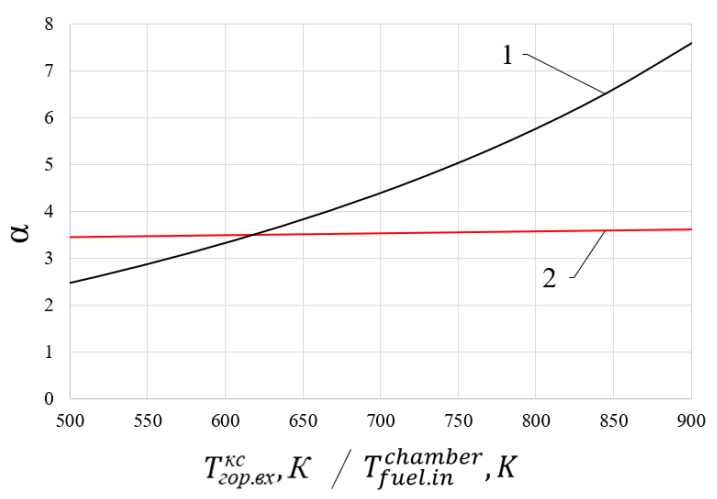

д) $g_{\text {бал }}=79 \mathrm{wt} \%$

e) ballast fractions 79 mas \%

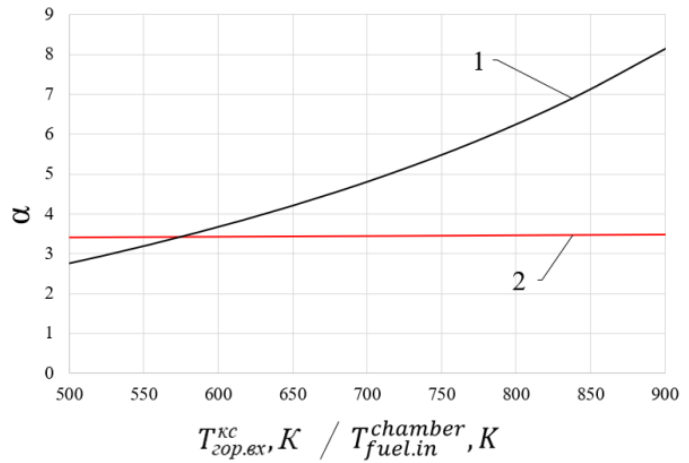

б) $g_{\text {бал }}=15$ мас. $\%$

b) ballast fractions $15 \mathrm{wt} . \%$

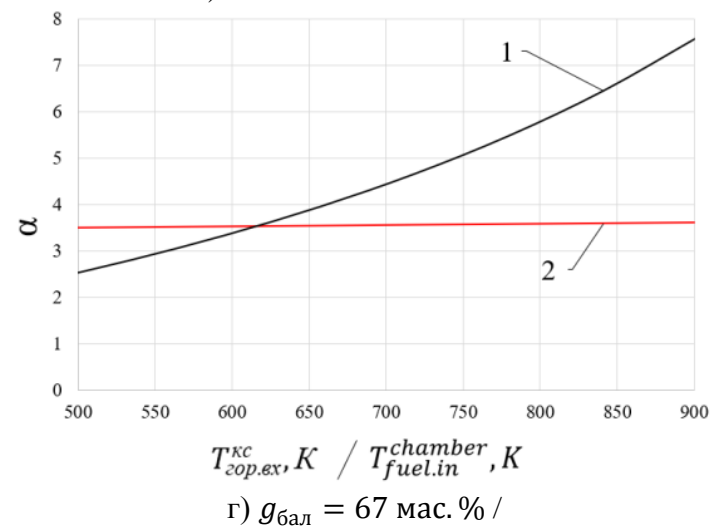

d) ballast fractions $67 \mathrm{wt} . \%$

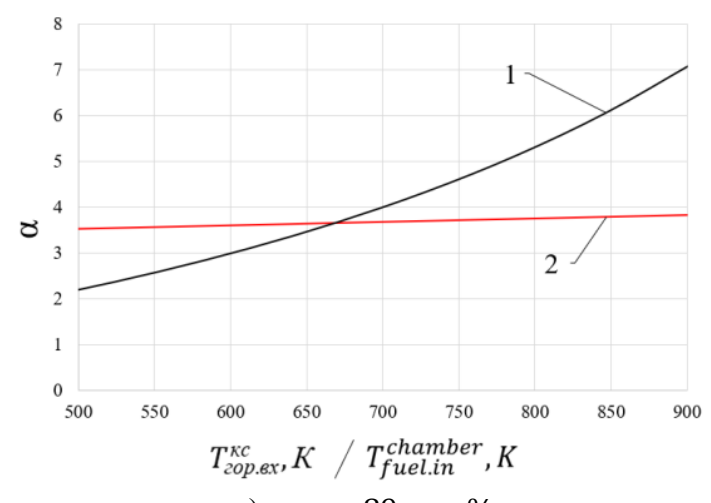

e) $g_{\text {бал }}=89$ мас. $\%$

f) ballast fractions $89 \mathrm{wt} . \%$

Рис. 2. Влияние температуры подачи забалластированных нефтяных газов на предель горения: 1 - коэффициент избытка окислителя на нижнем пределе горения $\left(\alpha_{H}\right) ; 2$ - коэффициент избытка окислителя в камере сгорания по параметрам установки ( $\left.\alpha_{\Gamma т у}\right)$

Fig. 2. Influence of the feed temperature of ballasted petroleum gases on the combustion limits: 1-oxidizer excess ratio at the lower combustion limit $\left(\alpha_{\text {lower }}\right) ; 2$ - oxidizer excess ratio in the combustion chamber according to the installation parameters $\left(\alpha_{G T U}\right)$

На рис. 3 приведены зависимости минимальной температуры подогрева и коэффициента рекуперации подогревателя от процента забалластированности, рассчитанные для энергоустановок с различной степенью сжатия $\varepsilon$ на компрессорах.

Обработка данных показывает, что с увеличением забалластированности НГ потребная минимальная температура подогрева возрастает. При содержании балластирующих компонентов более 80 \% наблюдается интенсивный (резкий) рост этой температуры. По данным $[27,30]$ увеличение температуры топлив- ного газа в 2 раза требует увеличения поверхности теплообмена и, соответственно, габаритов в 10 раз. Следовательно, для утилизации подогретого топливного газа с содержанием балластирующих компонентов более 80 \% потребуются теплообменные аппараты больших габаритов. Поэтому целесообразна утилизация нефтяных газов с содержанием балластирующих компонентов менее $80 \%$.

Для разработки универсального теплообменникаподогревателя топливного газа в составе энергоустановки с заданным значением степени сжатия $\varepsilon$ требу- 


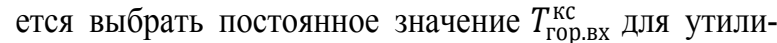
зации НГ с различным содержанием балластирующих компонентов.
В качестве примера на рис. 4 показан способ выбора значения $T_{\text {гор.вх }}^{\text {кс }}$ для энергоустановки со степенью сжатия $\varepsilon=3$.

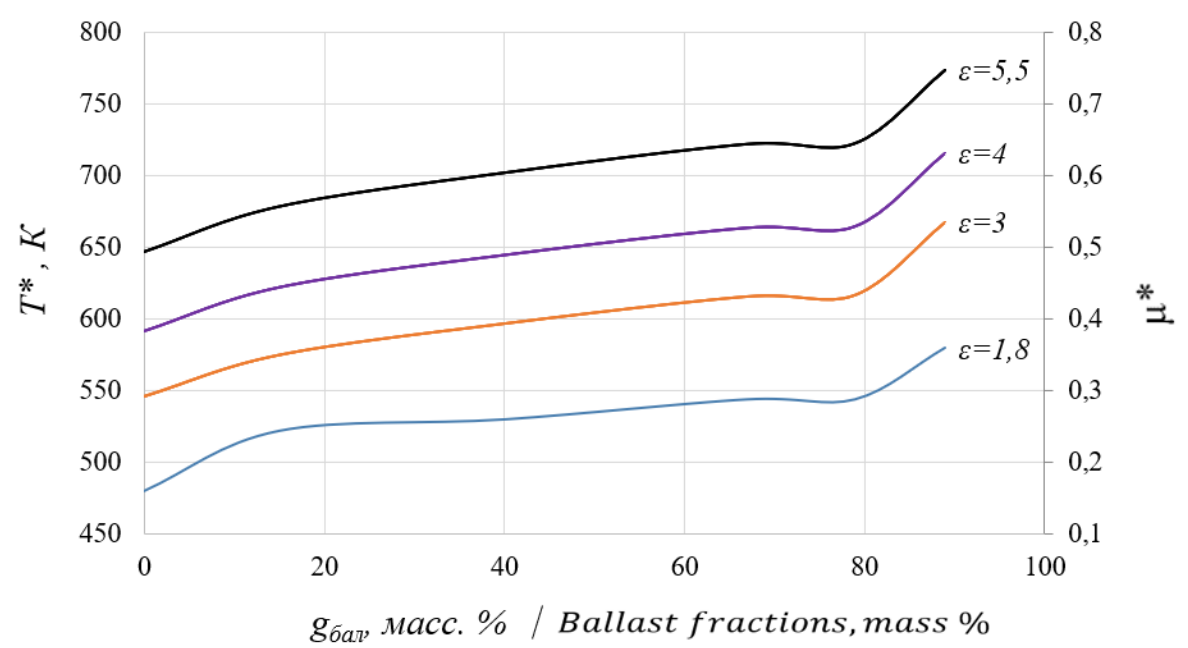

Pис. 3. Режимные параметры подогревателя топливного газа для семейства турбокомпрессоров (T* - минимальная температура подогретого топливного газа, при которой начинается устойчивое горение в утилизационной камере сгорания; $\mu^{*}$ - коэффициент рекуперачии нагревателя)

Fig. 3. Operating parameters of the fuel gas heater for a family of turbochargers ( $T^{*}$ - minimum temperature of heated fuel gas at which stable combustion starts in the utilization combustion chamber; $\mu^{*}$ - heater recuperation factor)

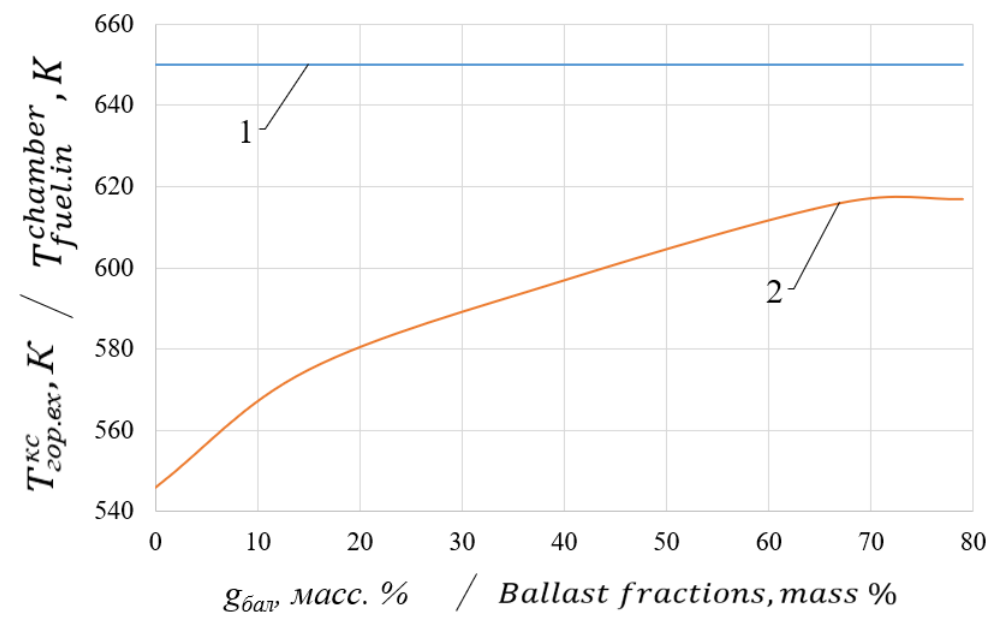

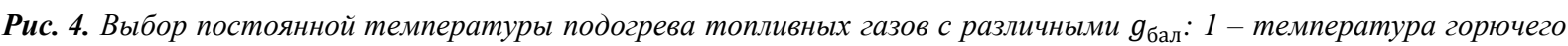
на входе в камеру сгорания; 2 - минимальная температура подогретого топливного газа, при которой начинается устойчивое горение в камере сгорания

Fig. 4. Selection of a constant temperature for heating fuel gases with different ballast fractions: 1 -fuel temperature at the inlet to the combustion chamber; 2 - minimum temperature of heated fuel gas at which stable combustion starts in the utilization combustion chamber

Универсальная температура подачи топливного газа в КС $T_{\text {гор.вх }}^{\text {кс }}$ выбирается с запасом $\Delta=T_{\text {гор.вх }}^{\text {кс }}-T^{*}$ по отношению к минимальной возможной температура $T^{*}$.Этот запас уменьшается по мере возрастания забалластированности НГ и минимальный запас $\Delta_{\min }=5 \%$ при $g_{\text {бал }}=80$ мас. \%.

Для каждой энергоустановки с заданной степенью сжатия $\varepsilon$ универсальная температура $T_{\text {гор.вх }}^{\text {кс }}$ будет иметь свое значение. На рис. 5 показаны значения этой температуры для семейства энергоустановок с различными степенями сжатия $\varepsilon$.
С увеличением степени сжатия на компрессоре потребное значение $T_{\text {гор.вх }}^{\text {кс }}$ возрастает. Следовательно, с увеличением мощности утилизационной энергоустановки будут возрастать габариты теплообменника-подогревателя топливного газа. Выбранные значения $T_{\text {гор.вх }}^{\text {кс }}$ на рис. 5 носят рекомендательный характер.

На рис. 6 представлены значения $\alpha_{\text {Гту }}$, соответствующие выбранным значениям $T_{\text {гор.вх }}^{\text {кс }}$ для энергоустановок различной мощности с различными значениями $\varepsilon$. 


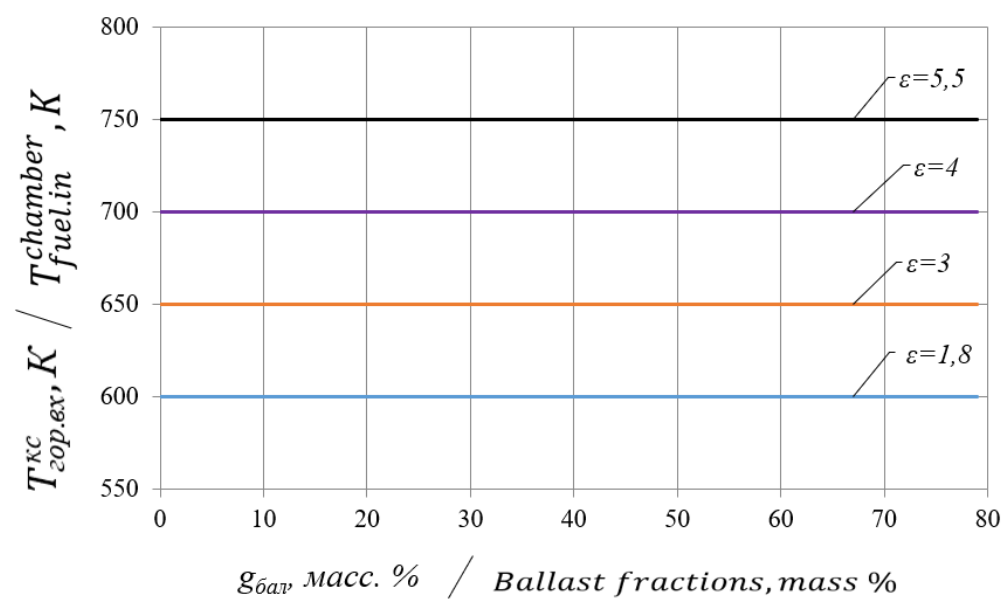

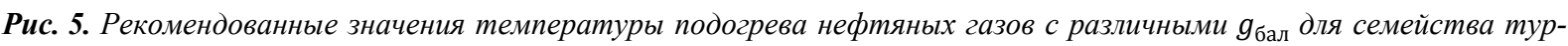
бокомпрессоров

Fig. 5. Recommended temperature values for preheating oil gases with different proportions of ballast for a family of turbochargers

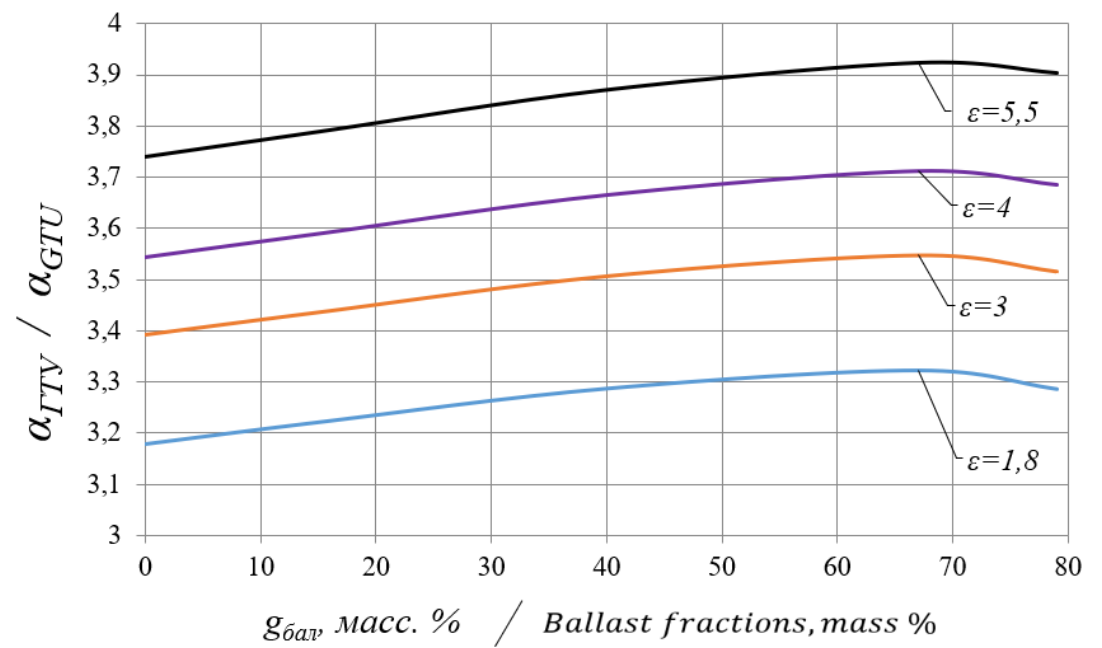

Pис. 6. Коэффициенты избытка окислителя в камере сгорания при утилизаџии нефтяных газов с различными $g_{\text {бал }}$ для семейства турбокомпрессоров

Fig. 6. Excess air ratios in the combustion chamber for the utilization of petroleum gases with different ballast contents for a family of turbochargers

Обработкарезультатов показывает, что для поддержания постоянной температуры рабочего тела на входе в турбину на каждом месторождении при эксплуатации универсальной ГТУ необходимо будет подбирать определенные значения расхода топливного газа при заданной частоте вращения компрессора.

Проведен параметрический анализ мощностных и расходных характеристик ГТУ при постоянной эффективной работе. При заданной полезной мощности $N_{\text {пол }}$

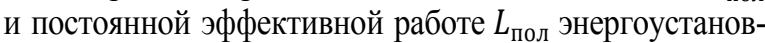
ки (при $\varepsilon=$ const) суммарный расход рабочего тела через

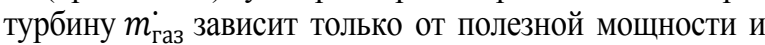
не зависит от процента забалластированности. С изменением содержания балластирующих компонентов при $T_{\text {газ.вх }}^{\mathrm{T}}=$ const изменяется потребный коэффициент

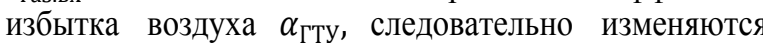

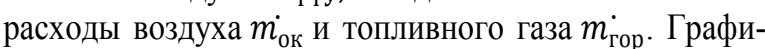
ческие зависимости $m_{\text {газ }}^{\cdot}=f\left(g_{\text {бал }}\right), m_{\text {ок }}=f\left(g_{\text {бал }}\right)$ и $m_{\text {гор }}^{\cdot}=f\left(g_{\text {бал }}\right)$ представлены на рис. 7 .
В однозонной КС именно суммарный расход $m_{\text {газ }}$ с определяет расходную скорость газо-воздушной смеси (ГВС) через поперечное сечение камеры. Для сохранения устойчивости пламени требуется поддержание определенного значения соотношения

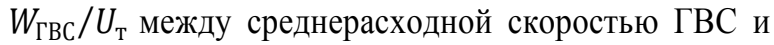
скоростью турбулентного горения, которое в сильной степени зависит от диаметра камеры сгорания. На рис. 8 представлены диаметры камеры сгорания для мощностного ряда ГТУ при утилизации топливных газов с разным содержанием балластирующих компонентов.

Обработкарезультатов показывает, что для утилизации топливных газов с различным содержанием балластирующих компонентов на разных месторождениях возможно использование универсальной камеры с постоянным диаметром при заданной мощности установки. 


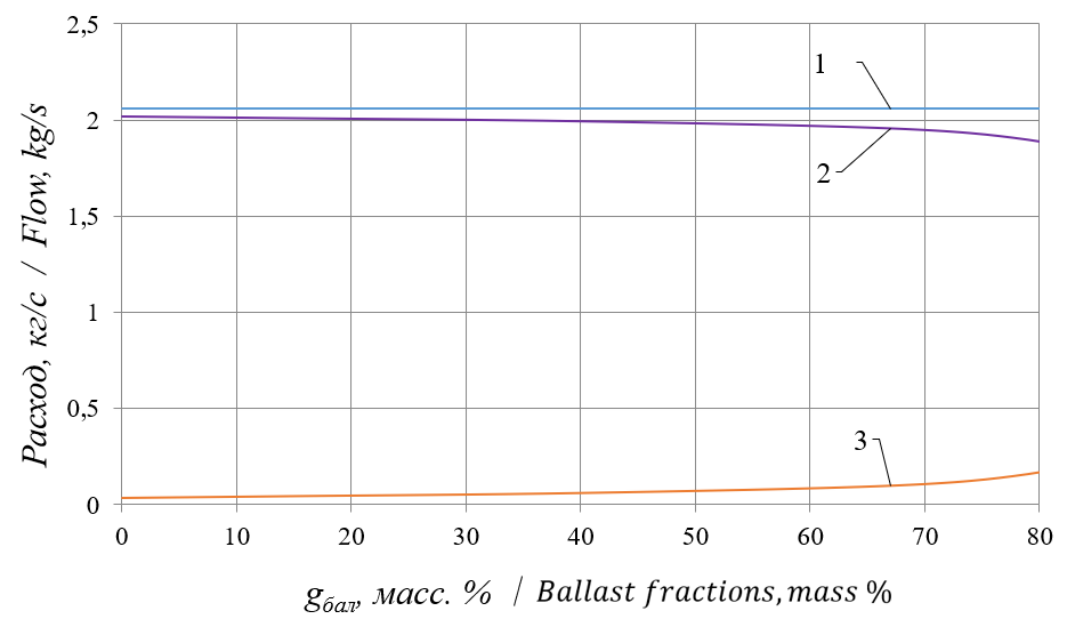

Рис. 7. Расходные характеристики энергоустановки при сжигании нефтяных газов с различнымсодержанием балластирующих компонентов при коэффищиенте избытка окислителя $\alpha=3$ и мощности энергоустановки $N=300 \kappa B m: 1$ - расход рабочего тела через турбину; 2 - расход окислителя; 3 - расход горючего

Fig. 7. Consumption characteristics of the power unit when burning oil gas with different content of ballast components at the oxidizer excess ratio $\alpha=3$ and power unit capacity $N=300 \mathrm{~kW}: 1$ - working body flow through the turbine; 2 oxidizer flow; 3 - fuel flow

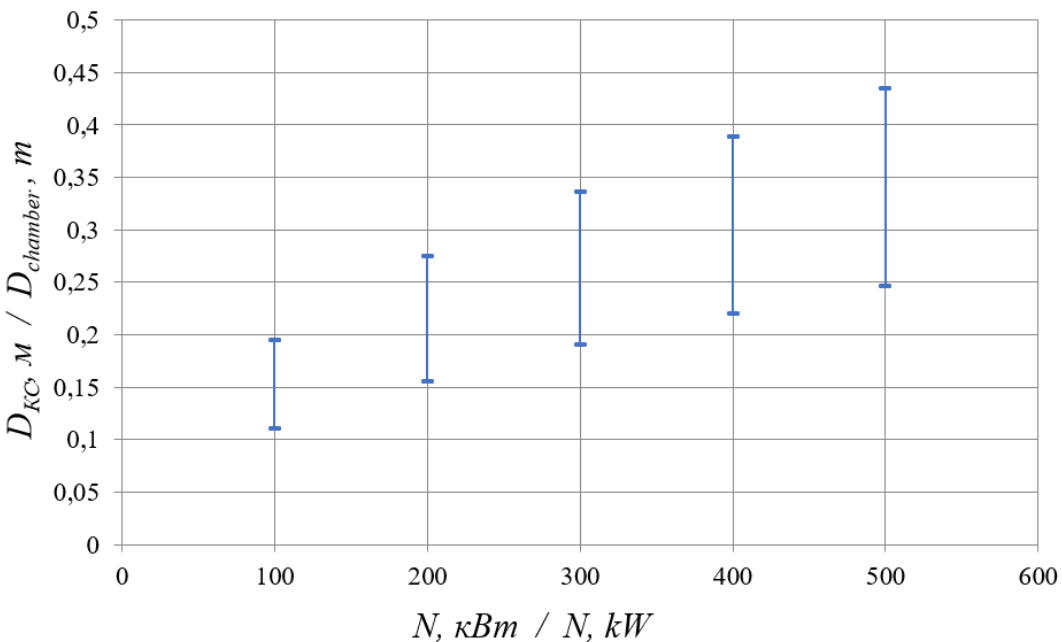

Pис. 8. Возможные диаметры камеры сгорания в зависимости от мощности ГТУ

Fig. 8. Combustion chamber diameters at different capacities of the gas turbine unit

\section{Выводы}

Исходя из проведенных исследований и обработанных данных можнопредложить следующие выводы:

- для обеспечения низкотемпературного бедного малоэмиссионного горения требуется внешний подогреватель топливного газа в составе энергоустановки, параметры которого влияют на режимные параметры камеры сгорания;

- рассмотрено влияние содержания балластирующих компонентов в подогретом топливном газе на коэффициент избытка воздуха и расходные характеристики окислителя и горючего в камере сгорания;

\section{СПИСОК ЛИТЕРАТУРЫ}

1. Иноземцев А.А., Нихамкин М.А., Сандрацкий В.Л. Основы конструирования авиационных двигателей и энергетических установок. - М.: Машиностроение, 2008. - Т. 2. - 368 с.

2. Гриценко Е.А., Данильченко В.П., Лукачев С.В. Конвертирование авиационных ГТД в газотурбинные установки наземно-
- показано, что при низкотемпературном горении топливного газа в газотурбинной установке заданной мощности с однозонной камерой сгорания устойчивое положение фронта пламени определяется суммарным расходом газо-воздушной смеси и не зависит от процента балласта;

- по условию устойчивого положения фронта пламени определены возможные диапазоны диаметров камеры сгорания для мощностного ряда газотурбинных энергоустановок при утилизации топливных газов с различным содержанием балластирующих компонентов.

го применения. - Самара: Изд-во Самарский научный центр PAH, 2004. - $271 \mathrm{c}$.

3. Бетинская О.А. Организация рабочего процесса в универсальной камере сгорания газотурбинной установки для утилизации попутного нефтяного газа: дис. ... канд. тех. наук. - Пермь, 2017. $-146 \mathrm{c}$. 
4. Анализ геометрических и тепловых характеристик высокоресурсной утилизационной камеры сгорания / О.О. Матюнин, А.А. Шилова, Н.Л. Бачев, Р.В. Бульбович // Вестник ПНИПУ. Аэрокосмическая техника. - 2018. - № 52. - С. 85-96.

5. Massey J.C., Chen Z.X., Swaminathan N. Lean flame root dynamics in a gas turbine model combustor // Combustion Science and Technology. - 2019. - V. 191. - P. 1019-1042.

6. Комаров Е.М. Методы уменьшения эмиссии вредных веществ в камерах сгорания ГТД и ГТУ // Машиностроение и компьютерные технологии. - 2018. - № 5. - С. 9-29.

7. Inanc E., Proch F., Kempf A.M. Studying transient jet flames by high-resolution LES using premixed flamelet chemistry// Direct and Large-Eddy Simulation XI. ERCOFTAC Series. - 2019. V. 25. - P. 237-243.

8. Экспериментальные исследования модельной двузонной малоэмиссионной камеры сгорания ГТУ средней мощности / Л.А. Булысова, В.Д. Васильев, М.Н. Гутник, К.С. Пугач, М.М. Гутник, А.Л. Берне // Электрические станции. - 2019. № 9 (1058). - C. $2-7$.

9. Experimental investigation of NOx emission from a sequential combustor with the kinetic second zone // L.A. Bulysova, V.D. Vasilev, M.N. Gutnik, A.L. Berne // Thermal Engineering. 2019. - V. 66. - № 7. - P. 498-504.

10. Experimental studies of NOx emissions in sequential fuel combustion with a diffusion second zone // L.A. Bulysova, V.D. Vasilev, M.N. Gutnik, A.L. Berne // Thermal Engineering. 2019. - V. 66. - № 6. - P. 402-408.

11. Обеспечение малоэмиссионной работы камеры сгорания в широком диапазоне климатических условий применительно к авиапроизводным ГТУ /Л.А. Булысова, А.Г. Тумановский, М.Н. Гутник, В.Д. Васильев, А.М. Сипатов, А.Д. Нугуманов // Электрические станции. - 2019. - № 12 (1061). - С. 20-22.

12. Расширение пределов горения в пористой горелке с помощью внешнего подогрева / Ал.Ал. Берлин, А.С. Штейнберг, С.М. Фролов, А.А. Беляев, В.С. Посвянский, В.Я. Басевич // Доклады Академии наук. - 2006. - Т. 406. - № 6. - С. 1-6.

13. Экспериментальное исследование расширения бедного предела горения метана с помощью внешних воздействий на физико-химические процессы в зоне прогрева пламени / П.А. Гусев, С.М. Фролов, О.Г. Скрипник, А.С. Штейнберг, А.А. Берлин // Горение и взрыв. - 2009. - Вып. 2. - С. 7-11.

14. Фролов С.М. Наука о горении и проблемы современной энергетики // Российский химический журнал. - 2008. - Т. 52. № 6. - С. 129-133.

15. Моделирование поверхностного горения на плоской пористой матрице/ В.С. Арутюнов, А.А. Беляев, Б.В. Лидский, А.В. Никитин, В.С. Посвянский, В.М. Шмелев // Горение и взрыв. 2018. - T. 11. - № 3. - C. 12-20.

16. Николаев В.М., Шмелев В.М.Поверхностное горение в объемной матрице из пенометалла с керамическим покрытием // Горение и взрыв. - 2015. - Т. 8. - № 1. - С. 50-56.

17. Новый тип малоэмиссионных камер сгорания для газотурбинных установок на основе объемных проницаемых матриц / А.Н. Рахметов, В.М. Шмелев, А.А. Захаров, В.С. Арутюнов // Горение и взрыв. - 2013. - № 6. - С. 61-64.
18. Рахметов А.Н., Шмелев В.М., Арутюнов В.С. Низкоэмиссионные камеры сгорания ГТУ на основе проницаемых объемных матриц // Горение и плазмохимия. - 2013. - Т. 11. № 2. - C. 83-91.

19. Wierzba I., Kilchyk V. Flammability limits of hydrogen-carbon monoxide mixtures at moderately elevated temperatures /I International Journal of Hydrogen Energy. - 2001. - V. 26. - Iss. 6. P. 639-643.

20. Gibbon H.J., Wainwright J., Rogers R.L. Experimental determination of flammability limits of solvents at elevated temperatures and pressures // Institution of Chemical Engineers Symposium Series. - 1994. - V. 134. -P. 1-12.

21. Effect of low temperature on the flammability limits of methane/nitrogen mixtures / Z. Li,M. Gong, E. Sun, J. Wu, Y. Zhou // Energy. - 2011. - V. 36 (9). - P. 5521-5524.

22. Dependence of the lower flammability limit on the initial temperature / T.A. Bolshova, V.A. Bunev, D.A. Knyazkov, O.P. Korobeinichev, A.A. Chernov, A.G. Shmakov, S.A. Yakimov // Combustion, Explosion, and Shock Waves. - 2012. - V. 48. Iss. 2. - P. 125-129.

23. Catoire L., Naudet V. Estimation of temperature dependent lower flammability limit of pure organic compounds in air at atmospheric pressure // Process Safety Progress. - 2005. V. 24 (2). - P. 130-137.

24. Liu Xueling, Zhang Qi Influence of initial pressure and temperature on flammability limits of hydrogen-air // International Journal of Hydrogen Energy. - 2014. - V. 39. - Iss. 12. - P. 6774-6782.

25. Burning velocities and flammability limits of gaseous mixtures at elevated temperatures and pressures/ Yu.N. Shebeko, S.G. Tsarichenko, A.Ya. Korolchenko, A.V. Trunev, V.Yu. Navzenya, S.N. Papkov, A.A. Zaitzev // Combustion and Flame. - 1995. V. 102. - Iss. 4. - P. 427-437.

26. Влияние состава и параметров подачи нефтяного газа на пределы горения в утилизационной камере сгорания газа / А.А. Шилова, Р.В. Бульбович, Н.Л. Бачев, О.О. Матюнин // Вестник ПНИПУ. Аэрокосмическая техника. - 2020. - № 60. C. 64-71.

27. Организация низкотемпературного бедного горения утилизируемого газа / Н.Л. Бачев, А.А. Шилова, О.О. Матюнин, Р.В. Бульбович // Проблемы региональной энергетики. - 2020. - № 3 (47). - C. 56-68.

28. Шилова А.А., Бачева Н.Ю. Определение коэффициентов избытка воздуха на верхнем и нижнем пределах горения забалластированных нефтяных газов // Вестник ПНИПУ. Аэрокосмическая техника. - 2018. - № 53. - С. 77-85.

29. Andrés Z.M., DeJoão A.C. Jr., Christian R.C. Method for determination of flammability limits of gaseous compounds diluted with $\mathrm{N}_{2}$ and $\mathrm{CO}_{2}$ in air //Fuel. - 2018. - V. 226. - P. 65-80.

30. Расчетно-экспериментальные исследования концентрационных пределов горения попутных нефтяных газов / Н.Л. Бачев, О.О. Матюнин, Р.В. Бульбович, О.А. Бетинская, А.А. Шилова // Проблемы региональной энергетики. - 2019. - № 2 (43). C. $39-47$.

Поступила 22.09.2021 2.

\section{Информация об авторах}

Шилова А.А., аспирант кафедры ракетно-космической техники и энергетических систем Пермского национального исследовательского политехнического университета.

Бачев Н.Л., кандидат технических наук, доцент кафедры ракетно-космической техники и энергетических систем Пермского национального исследовательского политехнического университета. 
UDC 665.612 .2

\title{
UTILIZATION OF HETEROGENEOUS PETROLEUM GASES IN A UNIVERSAL LOW-EMISSION GAS TURBINE UNIT WITH EXTERNAL FUEL GAS HEATING
}

\author{
Alena A. Shilova1, \\ alyona1203@gmail.com \\ Nikolay L. Bachev1, \\ bn154@yandex.ru \\ 1 Perm National Research Polytechnic University, \\ 29, Komsomolsky avenue, Perm, 614990, Russia.
}

The relevance of the study is caused by the need to create domestic gas turbine power plants with a universal low-emission combustion chamber for utilization of petroleum gases with different content of ballast components. Recently, various ways of reducing the emission of harmful substances in gas turbine engines (homogeneous combustion, injection of water or steam, diffusion combustion according to the $R Q Q L$ scheme, etc.) have been proposed and investigated. In this paper, the authors have proposed and investigateda variant of lowtemperature and low-emission combustion with external heating of petroleum gas before its feeding into the utilization combustion chamber.

Objective: to develop thermodynamic models for determining the operating parameters of the utilization power plant with fuel gas preheater in its composition and to identify the influence of the degree of oil gas ballast on the excess air and flow characteristics in the combustion chamber for the power range of power plants.

Objects: utilization gas turbine power plant, fuel gas preheater, low-emission combustion chamber.

Methods: thermodynamic modeling of the utilizing gas turbine unit with oil gas preheater before it is fed into the combustion chamber and thermodynamic calculation of parameters of low-temperature low-emission combustion of depleted gas-air mixture.

Results. Operating parameters of the utilization gas turbine unit and fuel gas preheater in its composition were obtained. For petroleum gases with different content of ballasting components, the minimum heating temperatures are determined at which stable combustion is possible. The required values of the excess air ratio and flow characteristics for the family of power plants have been determined. Recommendations are given for the choice of the combustion chamber diameter for the power range of utilizing power plants.

\section{Key words:}

Ballasted fuel gas, low-temperature low-emission combustion, external heating of fuel gas, stable combustion, power range of plants.

\section{REFERENCES}

1. Inozemtsev A.A., Nikhamkin M.A., Sandratskiy V.L. Osnovy konstruirovaniya aviatsionnykh dvigateley $i$ energeticheskikh ustanovok [Fundamentals of designing aircraft engines and power plants]. Moscow, Mashinostroenie Publ., 2008.Vol. 2, 368 p.

2. Gritsenko E.A., Danilchenko V.P., Lukachev S.V Konvertirovanie aviatsionnykh GTD v gazoturbinnye ustanovki nazemnogo primeneniya [Conversion of aircraft gas turbine engines into ground-based gas turbine units]. Samara, Samara Scientific Center RAN Publ., 2004. 271 p.

3. Betinskaya O.A. Organizatsiya rabochego protsessa v universalnoy kamere sgoraniya gazoturbinnoy ustanovki dlya utilizatsii poputnogo neftyanogo gaza. Dis. Kand. nauk [Organization of the working process in the universal combustion chamber of a gas turbine unit for utilization of associated petroleum gas. Cand. Diss.]. Perm, 2017. 146 p.

4. Matyunin O.O., Shilova A.A., Bachev N.L., Bulbovich R.V. Analysis of geometric and thermal characteristics of the highresource utilization combustion chamber. Bulletin of PNRPU. Aerospace engineering, 2018, no. 52, pp. 85-96. In Rus.

5. Massey J.C., Chen Z.X., Swaminathan N. Lean flame root dynamics in a gas turbine model combustor. Combustion Science and Technology, 2019, vol. 191, pp. 1019-1042.

6. Komarov E.M. Metody umensheniya emissii vrednykh veshchestv v kamerakh sgoraniya GTD i GTU [Methods for reducing the emission of harmful substances in the combustion chambers of gas turbine engines and gas turbines]. Mashinostroenie i kompyuternye tekhnologii, 2018, no. 5, pp. 9-29.

7. Inanc E., Proch F., Kempf A.M. Studying transient jet flames by high-resolution LES using premixed flamelet chemistry. Direct and LargeEddy Simulation XI. ERCOFTAC Series, 2019, vol. 25, pp. 237-243.

8. Bulysova L.A., Vasilyev V.D., Gutnik M.N., Pugach K.S., Gutnik M.M., Berne A.L. Experimental studies of a model twozone low-emission combustion chamber of a medium-power gas turbine unit. Electric stations, 2019, no. 9 (1058), pp. 2-7. In Rus.
9. Bulysova L.A., Vasilev V.D., Gutnik M.N., Berne A.L. Experimental investigation of $\mathrm{NO}_{\mathrm{x}}$ emission from a sequential combustor with the kinetic second zone. Thermal Engineering, 2019, vol. 66, no. 7, pp. 498-504.

10. Bulysova L.A., Vasilev V.D., Gutnik M.N., Berne A.L. Experimental studies of $\mathrm{NO}_{\mathrm{x}}$ emissions in sequential fuel combustion with a diffusion second zone. Thermal Engineering, 2019, vol. 66, no. 6, pp. 402-408

11. Bulysova L.A., Tumanovskiy A.G., Gutnik M.N., Vasilyev V.D., Sipatov A.M., Nugumanov A.D. Ensuring low-emission operation of the combustion chamber in a wide range of climatic conditions as applied to aircraft-derived gas turbine units. Electric stations, 2019, no. 12 (1061), pp. 20-22. In Rus.

12. Berlin Al.Al., Shteynberg A.S., Frolov S.M., Belyayev A.A., Posvyanskiy V.S., Basevich V.Ya. Rasshirenie predelov goreniya $\mathrm{v}$ poristoy gorelke $\mathrm{s}$ pomoshchyu vneshnego podogreva [Expansion of the limits of combustion in a porous burner using external heating]. Doklady Akademii nauk, 2006, vol. 406, no. 6, pp. 1-6.

13. Gusev P.A., Frolov S.M., Skripnik O.G., Shteynberg A.S., Berlin A.A. Eksperimentalnoe issledovanie rasshireniya bednogo predela goreniya metana s pomoshchyu vneshnikh vozdeystviy na fiziko-khimicheskie protsessy $\mathrm{v}$ zone progreva plameni [Experimental study of the expansion of the lean limit of combustion of methane with the help of external influences on the physicochemical processes in the heating zone of the flame]. Gorenie i vzryv, 2009, no. 2, pp. 7-11.

14. Frolov S.M. Nauka o gorenii i problem sovremennoy energetiki [Combustion science and problems of modern energy]. Rossiyskiy khimicheskiy zhurnal, 2008, vol. 52, no. 6, pp. 129-133.

15. Arutyunov V.S., Belyaev A.A., Lidskiy B.V., Nikitin A.V., Posvyanskiy V.S., Shmelev V.M. Modelirovanie poverkhnostnogo goreniya na ploskoy poristoy matritse [Simulation of surface combustion on a flat porous matrix]. Gorenie i vzryv, 2018, vol. 11, no. 3, pp. 12-20.

16. Nikolaev V.M., Shmelev V.M. Poverkhnostnoe gorenie v obemnoy matritse iz penometalla $s$ keramicheskim pokrytiem 
[Surface combustion in a volumetric foam metal matrix with a ceramic coating]. Gorenie i vzryv, 2015, vol. 8, no. 1, pp. 50-56.

17. Rakhmetov A.N., Shmelev V.M., Zakharov A.A., Arutyunov V.S. Novy tip maloemissionnykh kamer sgoraniya dlya gazoturbinnykh ustanovok na osnove obemnykh pronitsaemykh matrits [A new type of low-emission combustion chambers for gas turbine plants based on volumetric permeable matrices]. Gorenie i vzryv, 2013, no. 6, pp. 61-64.

18. Rakhmetov A.N., Shmelev V.M., Arutyunov V.S Nizkoemissionnye kamery sgoraniya GTU na osnove pronitsaemykh obemnykh matrits [Low-emission combustion chambers of gas turbines based on permeable volumetric matrices] Gorenie i plazmokhimiya, 2013, vol. 11, no. 2, pp. 83-91.

19. Wierzba I., Kilchyk V. Flammability limits of hydrogen-carbon monoxide mixtures at moderately elevated temperatures. International Journal of Hydrogen Energy, 2001, vol. 26, Iss. 6, pp. 639-643.

20. Gibbon H.J., Wainwright J., Rogers R.L. Experimenta determination of flammability limits of solvents at elevated temperatures and pressures. Institution of Chemical Engineers Symposium Series, 1994, vol. 134, pp. 1-12.

21. Li Z., Gong M., Sun E., Wu J., Zhou Y. Effect of low temperature on the flammability limits of methane/nitrogen mixtures. Energy, 2011, vol. 36 (9), pp. 5521-5524.

22. Bolshova T.A., Bunev V.A., Knyazkov D.A., Korobeinichev O.P., Chernov A.A., Shmakov A.G., Yakimov S.A. Dependence of the lower flammability limit on the initial temperature.Combustion, Explosion, and Shock Waves, 2012, vol. 48, Iss.2, pp 125-129.

23. Catoire L., Naudet V. Estimation of temperature dependent lower flammability limit of pure organic compounds in air at atmospheric pressure. Process Safety Progress, 2005, vol. 24 (2), pp. 130-137.
24. Xueling Liu, Qi Zhang. Influence of initial pressure and temperature on flammability limits of hydrogen-air. International Journal of Hydrogen Energy, 2014, vol. 39, Iss.12, pp. 6774-6782.

25. Shebeko Yu.N., Tsarichenko S.G., Korolchenko A.Ya., Trunev A.V., Navzenya V.Yu., Papkov S.N., Zaitzev A.A. Burning velocities and flammability limits of gaseous mixtures at elevated temperatures and pressures. Combustion and Flame, 1995 , vol. 102, Iss. 4, pp. 427-437.

26. Shilova A.A., Bulbovich R.V., Bachev N.L., Matyunin O.O. Influence of the composition and parameters of oil gas supply on the combustion limits in the gas utilization chamber. Bulletin of PNRPU. Aerospace engineering, 2020, no. 60, pp. 64-71. In Rus.

27. Bachev N.L., Shilova A.A., Matyunin O.O., Bulbovich R.V. Organization of low-temperature poor combustion of recycled gas. Problems of the regional energetics, 2020, no. 3 (47), pp. 56-68. In Rus.

28. Shilova A.A., Bacheva N.Yu. Determination of excess air coefficients at the upper and lower limits of combustion of ballasted oil gasesюBulletin of PNRPU. Aerospace engineering, 2018, no. 53, pp. 77-85. In Rus.

29. Andrés Z.M., De João A.C. Jr., Christian R.C.Method for determination of flammability limits of gaseous compounds diluted with $\mathrm{N} 2$ and $\mathrm{CO} 2$ in air. Fuel, 2018, vol. 226, pp. 65-80.

30. Bachev N.L., Matyunin O.O., Bulbovich R.V., Betinskaya O.A., Shilova A.A. Computational and experimental studies into concentration limits of associated petroleum gas combustion. Probleme le energetic i iregionale, 2019, no. 2(43), pp. 39-47.

Received: 22 September 2021.

Information about the authors

Alena A. Shilova, graduate student, Perm National Research Polytechnic University.

Nikolay L. Bachev, Cand. Sc., associate professor, Perm National Research Polytechnic University. 